\title{
Lateral seismic response of building frames considering dynamic soil-structure interaction effects
}

Article in Structural Engineering \& Mechanics · February 2013

DOI: 10.12989/sem.2013.45.3.311

CITATIONS

20

3 authors, including:

\section{Harry Far}

University of Technology Sydney

45 PUBLICATIONS 251 CITATIONS

SEE PROFILE
READS

878

Some of the authors of this publication are also working on these related projects:

Project

An Experimental and Numerical Investigation into the Compressibility and Settlement of Sand Mixed with TDA View project

Optimised Retrofitting Techniques to Improve Energy Efficiency of Existing Residential Buildings in Australia View project 


\title{
Lateral seismic response of building frames considering dynamic soil-structure interaction effects
}

\author{
S. Hamid RezaTabatabaiefar ${ }^{*}$, Behzad Fatahi ${ }^{a}$ and Bijan Samali ${ }^{b}$ \\ Centre for Built Infrastructure Research, University of Technology Sydney (UTS), Sydney, Australia
}

(Received November 22, 2011, Revised December 6, 2012, Accepted December 15, 2012)

\begin{abstract}
In this study, to have a better judgment on the structural performance, the effects of dynamic Soil-Structure Interaction (SSI) on seismic behaviour and lateral structural response of mid-rise moment resisting building frames are studied using Finite Difference Method. Three types of mid-rise structures, including 5, 10, and 15 storey buildings are selected in conjunction with three soil types with the shear wave velocities less than $600 \mathrm{~m} / \mathrm{s}$, representing soil classes $C_{e}, D_{e}$ and $E_{e}$, according to Australian Standard AS 1170.4. The above mentioned frames have been analysed under two different boundary conditions: (i) fixed-base (no soil-structure interaction), and (ii) flexible-base (considering soil-structure interaction). The results of the analyses in terms of structural lateral displacements and drifts for the above mentioned boundary conditions have been compared and discussed. It is concluded that the dynamic soil-structure interaction plays a considerable role in seismic behaviour of mid-rise building frames including substantial increase in the lateral deflections and inter-storey drifts and changing the performance level of the structures from life safe to near collapse or total collapse. Thus, considering soil-structure interaction effects in the seismic design of mid-rise moment resisting building frames, particularly when resting on soft soil deposit, is essential.
\end{abstract}

Keywords: dynamic soil-structure interaction; seismic behavior; lateral structural response; mid-rise moment resisting frames; soft soil deposit

\section{Introduction}

The importance of soil-structure interaction both for static and dynamic loads has been well established and the related literature covers at least 30 years of computational and analytical approaches to solving soil-structure interaction problems. Since 1990s, great effort has been made for substituting the classical methods of design by the new ones based on the concept of performance-based seismic design.

Dynamic response of structures supported on soft soil deposits may be different from the response of a similarly excited, identical structures supported on rigid ground. Obviously structures with flexible supports have more degrees of freedom and, therefore, different dynamic characteristics than the structures resting on the rigid ground. Additionally, a significant part of the

*Corresponding author, Research Assistant, E-mail: SeyedHamidReza.Tabatabaiefar@uts.edu.au

${ }^{\mathrm{a}}$ Senior Lecturer

${ }^{\mathrm{b}}$ Professor 
vibrational energy of the structures with flexible supports may be dissipated by radiation of waves into the supporting medium or by damping in the foundation material. Flexibility of soil causes lengthening of lateral natural period due to overall decrease in the lateral stiffness. Such lengthening could considerably alter the seismic response of the building frames resting on shallow foundations (Wolf 1985).

When shear wave velocity of the supporting soil is less than $600 \mathrm{~m} / \mathrm{s}$, effects of soilstructure interaction on seismic response of structural systems, particularly for moment resisting building frames, are significant (e.g., Veletsos and Meek 1974, Galal and Naimi 2008, Tabatabaiefar and Massumi 2010, Agrawal and Hora 2012). Wolf and Deeks (2004) summarised these effects as: (i) increase in natural period and damping of the system, (ii) increase in lateral displacements of the structure, and (iii) change in the base shear depending on the frequency content of the input motion and dynamic characteristics of the soil and the structure. Thus, for ordinary building structures, the necessity of a better insight into the physical phenomena involved in SSI problems has been emphasised. In this study, SSI effects on the performance level of mid-rise moment resisting buildings constructed on various soil types including soil types $\mathrm{C}_{\mathrm{e}}, \mathrm{D}_{\mathrm{e}}$, and $\mathrm{E}_{\mathrm{e}}$ according to the Australian Standards are investigated.

\section{Soil-structure system idealisation}

The method, in which the entire soil-structure system is modelled in a single step, is called Direct Method. The use of direct method requires a computer program that can treat the behaviour of both soil and structure with equal rigor simultaneously (Kramer 1996). A soil-structure system simulated using direct method composed of structure, common nodes, soil foundation system and earthquake induced acceleration at the level of the bed rock is shown in Fig.1.

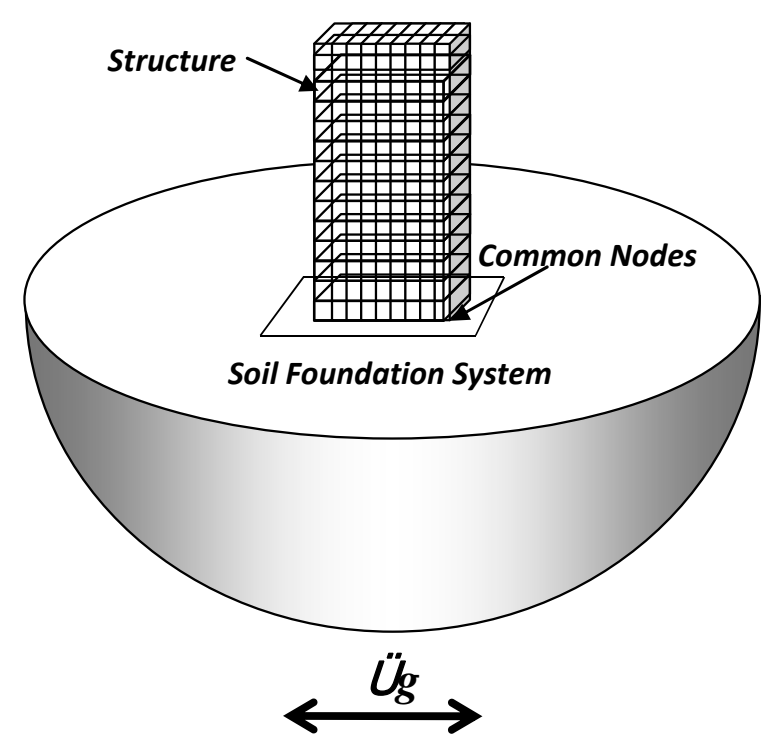

Fig. 1 Soil-structure system in direct method 
The dynamic equation of motion of the soil and structure system can be written as

$$
[M]\{\ddot{u}\}+[C]\{\dot{u}\}+[K]\{u\}=-[M]\{m\} \ddot{u}_{g}+\left\{F_{v}\right\}
$$

where, $\{u\}$, $\{\dot{u}\}$ and $\{\ddot{u}\}$ are the nodal displacements, velocities and accelerations with respect to the underlying soil foundation, respectively. $[M],[C]$ and $[K]$ are the mass, damping, and stiffness matrices of the structure, respectively. It is more appropriate to use the incremental form of Eq. (1) when plasticity is included, and then the matrix $[K]$ should be the tangential matrix and $\ddot{u}_{g}$ is the earthquake induced acceleration at the level of the bed rock. For example, if only the horizontal acceleration is considered, then $\{m\}=[1,0,1,0, \ldots, 1,0]^{T} .\left\{F_{v}\right\}$ is the force vector corresponding to the viscous boundaries.

The governing equations of motion for the structure incorporating foundation interaction and the method of solving these equations are relatively complex. Therefore, direct method is employed in this study and finite difference software, FLAC2D, is utilised to model the soil-structure system and to solve the equations for the complex geometries and boundary conditions.

FLAC 2D (Fast Lagrangian Analysis of Continua) is a two-dimensional explicit finite difference program for engineering mechanics computations. This program can simulate the behaviour of different types of structures. Materials are represented by elements which can be adjusted to fit the geometry of the model. Each element behaves according to a prescribed linear or nonlinear stress/strain law in response to the applied forces or boundary restraints.

The soil-structure model (Fig. 2) comprises beam elements to model structural elements, two dimensional plane strain grid elements to model soil medium, fixed boundaries to model the bed rock, quiet boundaries (viscous boundaries) to avoid reflective waves produced by the soil lateral boundaries, and interface elements to simulate frictional contact and probable slip due to seismic excitation. According to Rayhani and Naggar (2008), horizontal distance between soil boundaries is assumed to be five times the structural width $(60 \mathrm{~m})$. As the most amplification

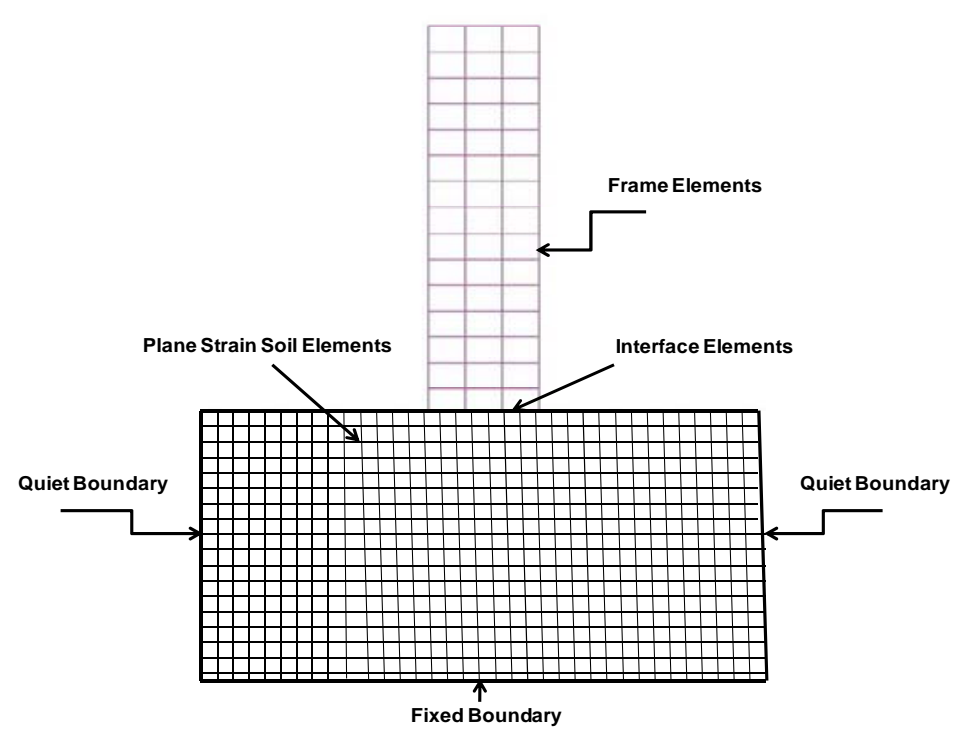

Fig. 2 Components of the Soil-Structure model in FLAC 2D 
occurs within the first $30 \mathrm{~m}$ of the soil profile, which is in agreement with most of modern seismic codes (e.g., ATC-40 1996, NEHRP 2003), bed rock depth is assumed to be $30 \mathrm{~m}$.

The foundation facing zone in numerical simulations is separated from the adjacent soil zone by interface elements. The interfaces between the foundation and soil is represented by normal $\left(K_{n}\right)$ and shear $\left(K_{s}\right)$ springs between two planes contacting each other and is modelled using linear spring-slider systems, with the interface shear strength defined by the MohrCoulomb failure criterion (Fig. 3). The relative interface movement is controlled by interface stiffness values in the normal and tangential directions. As recommended by Itasca Consulting Group (2008), normal and shear spring stiffness values are set to ten times the equivalent stiffness of the neighbouring zone.

The foundation slab which is $4 \mathrm{~m}$ wide and $12 \mathrm{~m}$ long is modelled using a frame element with structural properties similar to the structural model. As it is a plane strain problem, shallow foundation width has been taken into account to calculate the moment of inertia of the footing $\left(E A=18.6 \times 10^{7} \mathrm{kN}, E I=3.48 \times 10^{7} \mathrm{kN} . \mathrm{m}^{2}\right)$

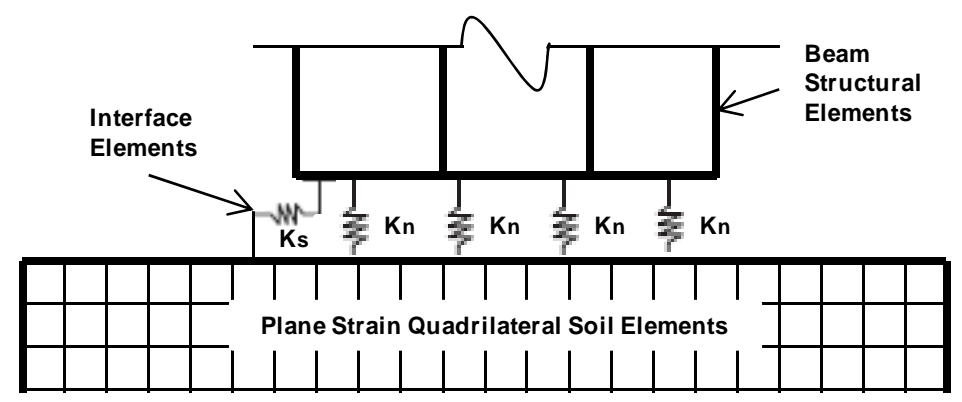

Fig. 3 Interface elements connected by normal $\left(K_{n}\right)$ and shear $\left(K_{s}\right)$ stiffness springs

\section{Characteristics of models}

In this study, three structural models, consisting of 5, 10, and 15 story models, representing conventional types of mid-rise moment resiting building frames have been selected in conjunction with three soil types with the shear wave velocities less that $600 \mathrm{~m} / \mathrm{s}$. The selected soils comprise one cohesionless and two cohesive soils, representing classes $C_{e}, D_{e}$ and $E_{e}$, according to the classification criteria listed in Section 4 of AS 1170.4 (Earthquake action in Australia).

The structural type of the building frames is intermediate moment-resiting frames (moderately ductile) with the following factors for elastic analysis according to Table 6.5(A) of AS 1170.4 (Earthquake action in Australia):

Structural Ductility Factor $(\mu)=3.0$

Performance Factor $\left(S_{p}\right)=0.67$

It should be noted that considering the above mentioned factors for structural ductility and performance of the building frames, elastic time history dynamic analysis has been employed in this study. Dimensional characteristics of the mentioned frames are summarised in Table 1. 
Table 1 Dimensional characteristics of the studied frames

\begin{tabular}{ccccccc}
\hline $\begin{array}{c}\text { Reference } \\
\text { Name (Code) }\end{array}$ & $\begin{array}{c}\text { Number } \\
\text { Of Stories }\end{array}$ & $\begin{array}{c}\text { Number } \\
\text { Of Bays }\end{array}$ & $\begin{array}{c}\text { Story } \\
\text { Height }(\mathrm{m})\end{array}$ & $\begin{array}{c}\text { Story } \\
\text { Width (m) }\end{array}$ & $\begin{array}{c}\text { Total } \\
\text { Height }(\mathrm{m})\end{array}$ & $\begin{array}{c}\text { Total } \\
\text { Width (m) }\end{array}$ \\
\hline S5 & 5 & 3 & 3 & 4 & 15 & 12 \\
S10 & 10 & 3 & 3 & 4 & 30 & 12 \\
S15 & 15 & 3 & 3 & 4 & 45 & 12 \\
\hline
\end{tabular}

Structural sections are designed according to AS3600-2001 (Australian Standard for Concrete Structures) after undertaking elastic dynamic analysis under influence of four different earthquake ground motions, as fixed base models. Two near field earthquake acceleration records including Kobe (1995) and Northridge (1994) and two far field earthquake acceleration records comprising El-Centro (1940) and Hachinohe (1968) are selected and utilised in this study. These earthquakes have been chosen by the International Association for Structural Control and Monitoring for benchmark seismic studies (Karamodin and Kazemi, 2008). The characteristics of the earthquake ground motions are summarised in Table 2. It is assumed that the earthquake ground motions are bedrock records.

Table 2 Earthquake ground motions used in this study

\begin{tabular}{cccccc}
\hline \hline Earthquake & Country & Year & PGA (g) & Mw (R) & $\mathrm{T}_{(\mathrm{S})}$ Duration \\
\hline Northridge & USA & 1994 & 0.843 & 6.7 & 30.0 \\
Kobe & Japan & 1995 & 0.833 & 6.8 & 56.0 \\
El Centro & USA & 1940 & 0.349 & 6.9 & 56.5 \\
Hachinohe & Japan & 1968 & 0.229 & 7.5 & 36.0 \\
\hline
\end{tabular}

These earthquakes have been chosen by the International Association for Structural Control and Monitoring for benchmark seismic studies (Karamodin and Kazemi 2008).

Performance-based engineering (PBE) is a technique for seismic evaluation and design using performance level prediction for safety and risk assessment. Over the past few years, performancebased seismic design concepts have been employed by many researchers (e.g., Paul Smith-Pardo 2011, Tabatabaiefar et al. 2012). Seismic performance (performance level) is described by designating the maximum allowable damage state (damage parameter) for an identified seismic hazard (hazard level). Performance levels describe the state of structures after being subjected to a certain hazard level and are classified as: fully operational, operational, life safe, near collapse, or collapse (Vision 2000 1995, FEMA 273/274 1997). The above mentioned five qualitative performance levels are related to the corresponding quantitative maximum interstorey drifts (as a damage parameter) of: $<0 \cdot 2 \%,<0 \cdot 5 \%,<1 \cdot 5 \%,<2 \cdot 5 \%$, and $>2 \cdot 5 \%$, respectively. In this study, performance levels of the structural models are considered as 'life safe' indicating the maximum inter-storey drifts of $1.5 \%$.

The specified compressive strength of concrete, the specified yield strength of steel rebar, and the concrete density are assumed to be, $32 \mathrm{MPa}, 400 \mathrm{MPa}$, and $25 \mathrm{kN} / \mathrm{m}^{3}$, respectively. The modulus of elasticity of concrete $\left(E_{c j}\right.$, MPa) was calculated according to clause 6.1.2 of 
AS3600:2001 (Australian Standard for Concrete Structures) as follows

$$
E_{c j}=(\rho)^{1.5} \times\left(0.043 \sqrt{f_{c m}}\right)
$$

Where, $\rho$ is density of concrete $\left(\mathrm{kg} / \mathrm{m}^{3}\right)$ and $f_{c m}$ is the mean value of the compressive strength of concrete at the relevant age $(M P a)$.

Characteristics of the utilised soils are shown in Table 3. The subsoil properties have been extracted from actual in-situ and laboratory tests (Rahvar 2005, 2006a, b). Therefore, these parameters have merits over the assumed parameters which may not be completely conforming to reality. In addition, it is assumed that watertable is well below the ground surface.

Table 3 Geotechnical characteristics of the utilised soils in this study

\begin{tabular}{cccccccccc}
\hline \hline $\begin{array}{c}\text { Soil Type } \\
\text { (AS170) }\end{array}$ & $\begin{array}{c}\text { Shear } \\
\text { vave } \\
\text { velocity } \\
\text { Vs (m/s) }\end{array}$ & $\begin{array}{c}\text { Unified } \\
\text { classification }\end{array}$ & $\begin{array}{c}\text { Modulus } \\
G_{\max }(\mathrm{kPa})\end{array}$ & $\begin{array}{c}\text { Roisson's } \\
\text { Ratio }\end{array}$ & SPT & $\begin{array}{c}\text { Plastic } \\
\text { Index } \\
(\mathrm{PI})\end{array}$ & $\begin{array}{c}C^{\prime} \\
(\mathrm{kPa})\end{array}$ & $\begin{array}{c}\phi^{\prime} \\
\text { (Degree) }\end{array}$ & Reference \\
\hline $\mathrm{C}_{\mathrm{e}}$ & 600 & $\mathrm{GM}$ & 623,409 & 0.28 & $\mathrm{~N}>50$ & - & 5 & 40 & $\begin{array}{c}\text { Rahvar } \\
(2005)\end{array}$ \\
\hline $\mathrm{D}_{\mathrm{e}}$ & 320 & $\mathrm{CL}$ & 177,304 & 0.39 & 30 & 20 & 20 & 19 & $\begin{array}{c}\text { Rahvar } \\
(2006 \mathrm{a})\end{array}$ \\
\hline $\mathrm{E}_{\mathrm{e}}$ & 150 & $\mathrm{CL}$ & 33,100 & 0.40 & 6 & 15 & 20 & 12 & $\begin{array}{c}\text { Rahvar } \\
(2006 \mathrm{~b})\end{array}$ \\
\hline
\end{tabular}

The shear wave velocity values, shown in Table 3, have been obtained from down-hole test, which is a low strain in-situ test. This test generates a cyclic shear strain of about $10^{-4}$ percent where the resulting shear modulus is called $G_{\max }$. In the event of an earthquake, the cyclic shear strain amplitude increases and the shear strain modulus and damping ratio which both vary with the cyclic shear strain amplitude, change relatively. Vucetic and Dobry (1991) for cohesive soils and Seed and Idriss (1986) for cohesionless soils reported ready to use charts indicating the variations of the shear modulus ratio with the shear strain in nonlinear dynamic analysis as well as material damping ratio versus cyclic shear strain, adopted in this study.

\section{Numerical analysis}

Several efforts have been made in recent years in the development of analytical methods for assessing the response of structures and supporting soil media under seismic loading conditions. There are two main analytical procedures for dynamic analysis of soil-structure systems under seismic loads, equivalent-linear and fully nonlinear methods. Byrne et al. (2006), Beaty and Byrne (2001) provided some overviews of the above mentioned methods and discussed the benefits of the nonlinear numerical method over the equivalent-linear method for different practical applications. The equivalent-linear method is not appropriate to be used in dynamic soil-structure interaction analysis as it does not directly capture any 
nonlinearity effects due to linear solution process. In addition, strain-dependent modulus and damping functions are only taken into account in an average sense, in order to approximate some effects of nonlinearity. Byrne et al. (2006) concluded that the most appropriate method for dynamic analysis of soil-structure system is fully nonlinear method. The method correctly represents the physics associated with the problem and follows any stress-strain relation in a realistic way. In this method, small strain shear modulus and damping degradation of soil with strain level can be considered in the modelling precisely.

Considering the mentioned priorities and capabilities of the fully nonlinear method for dynamic analysis of soil-structure systems, this method is adopted in this study in order to attain rigorous and more reliable results. Dynamic analyses are carried out for two different systems: (i) fixed base structures on rigid ground (Fig. 4(a)); and (ii) frames on subsoil (Fig. 4(b)) employing direct method of soil-structure interaction analysis, called flexible base.

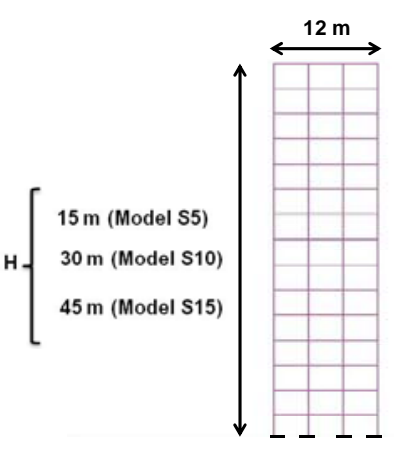

(a)

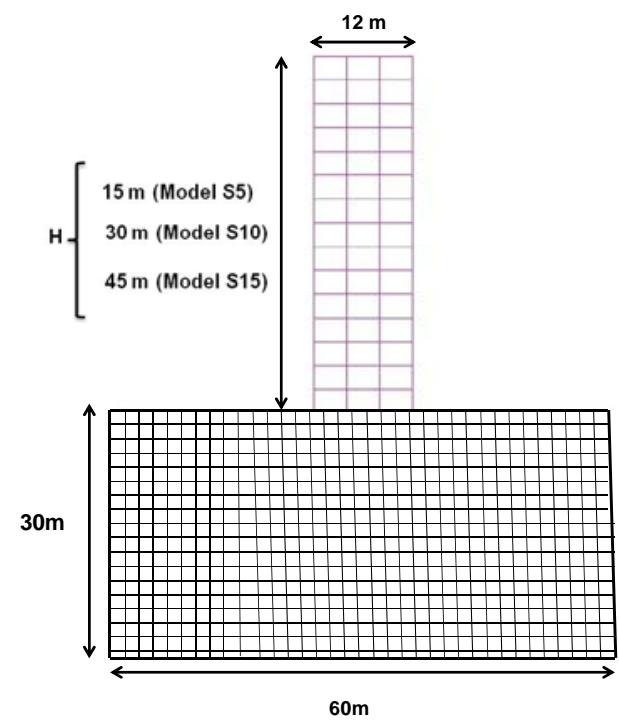

(b)

Fig. 4 Numerical models (a) fixed base model, (b) flexible base model

Earthquake ground motions shown in Table 2 are applied to both systems in two different ways. In the case of modelling the soil and structure simultaneously using direct method (flexible base), the earthquake records are applied to the combination of soil and structure directly at the bed rock level, while in the case of modelling the structure as fixed base (without soil), the earthquake records are applied to the base of the structural models.

\section{Results and discussions}

In order to have a comprehensive comparison between the results and draw a clear picture about the effects of subsoil rigidity on seismic response of mid-rise moment resisting building 
frames, average values of lateral deflections and inter-storey drifts under influence of four mentioned earthquakes (Table 2) have been determined. The average maximum lateral deflections and inter-storey drifts for 5, 10, and 15 storey models are shown in Figs. 5, 6, and 7, respectively.

Lateral deflections illustrated in Figs. 5(a), 6(a), and 7(a) represent average values of maximum elastic lateral deflections of each storey derived from FLAC 2D deflection history records. Interstorey drifts shown in Figs. 5(b), 6(b), and 7(b) are determined from corresponding average values of the maximum elastic lateral deflections (Figs. 5(a), 6(a), and 7(a)) for each two adjacent stories using equation 6.7 (1) of AS 1170.4 (Earthquake action in Australia) as follows

$$
\text { drift }=\left[\left(d_{i e+1}-d_{i e}\right) \times\left(\mu / S_{p}\right)\right] / h
$$

Where, $d_{i e+1}$ is deflection at $(i+1)$ level determined by elastic analysis, $d_{i e}$ is deflection at (i) level determined by elastic analysis, $\mu$ is Structural Ductility Factor, $S_{p}$ is Performance Factor, and $h$ is storey height.

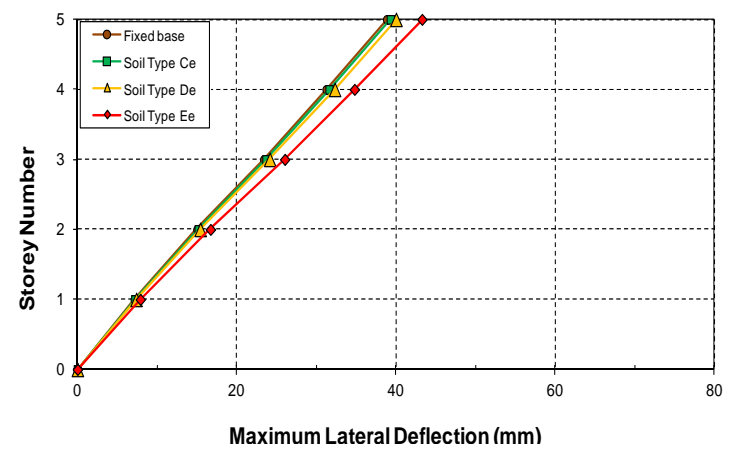

(a)

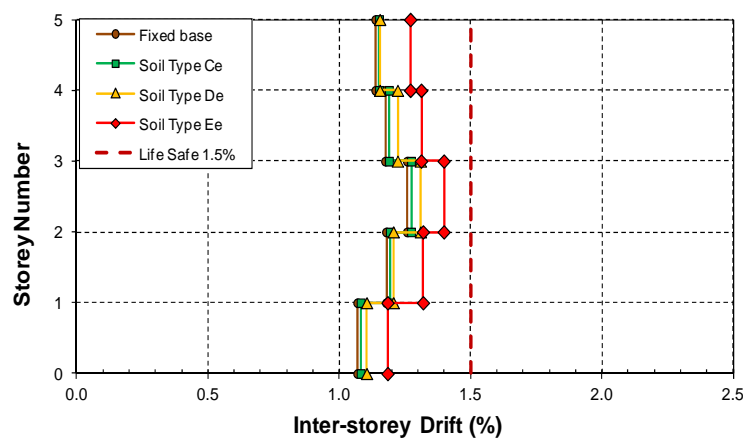

(b)

Fig. 5 Average results of dynamic analyses of model S5 (5 storey model) for two cases of fixed base and flexible base resting on three different subsoils (a) lateral deflections, (b) inter-storey drifts

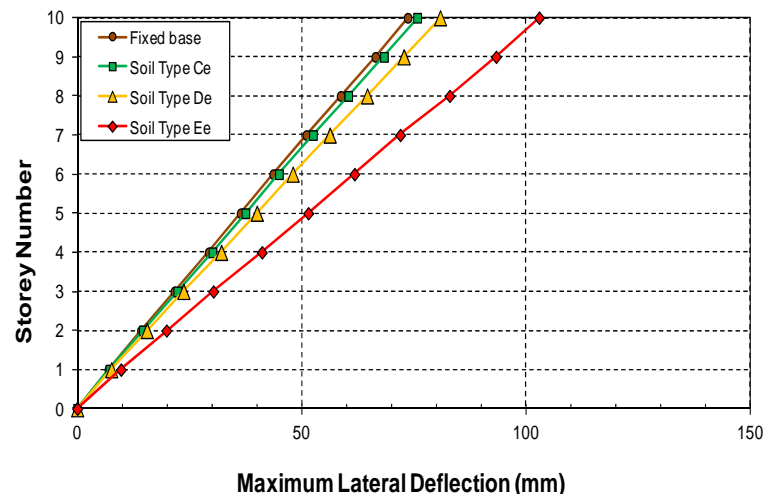

(a)

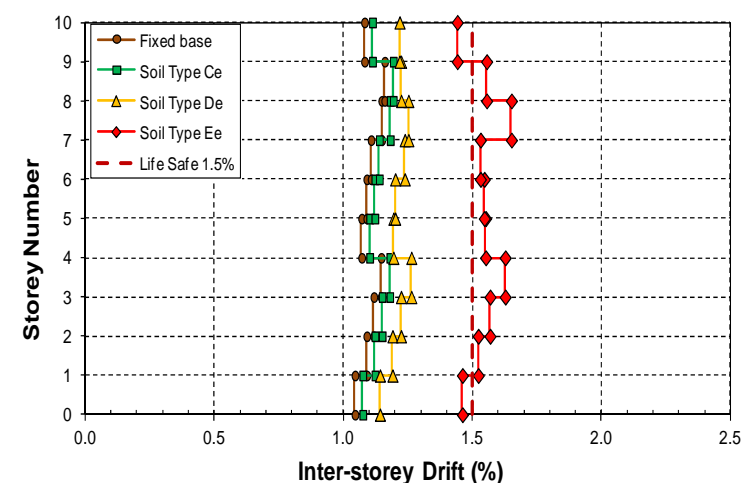

(b)

Fig. 6 Average results of dynamic analyses of model S10 (10 storey model) for two cases of fixed base and flexible base resting on three different subsoils (a) lateral deflections, (b) inter-storey drifts 


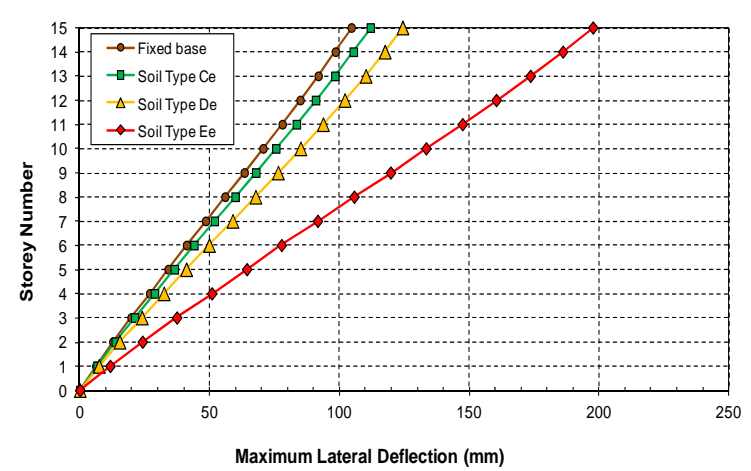

(a)

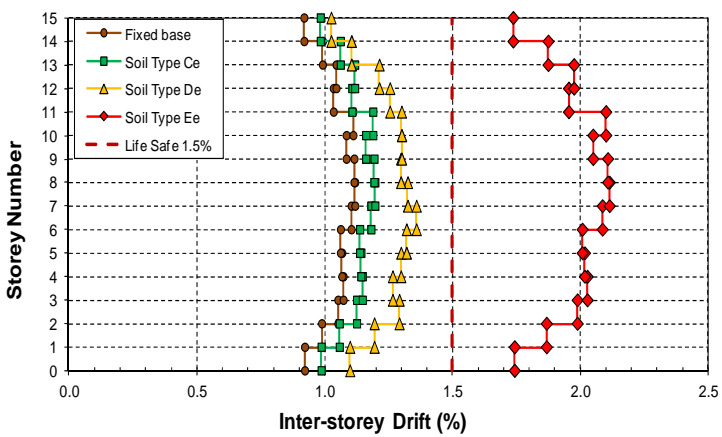

(b)

Fig. 7 Average results of dynamic analyses of model S15 (15 storey model) for two cases of fixed base and flexible base resting on three different subsoils (a) lateral deflections, (b) inter-storey drifts

Comparing the results for lateral deflections and inter-storey drifts of fixed-base and flexible-base models resting on soil classes $C_{e}, D_{e}$, and $E_{e}$, it is observed that lateral deflections and corresponding inter-storey drifts of the flexible base models resting on soil class $\mathrm{C}_{\mathrm{e}}$ have increased only by $1 \%, 3 \%$, and $7 \%$ in comparison to fixed-base models for models S5, S10, and S15, respectively. Thus, performance level of studied mid-rise moment resisting building frames resting on soil class $C_{e}$ remains in life safe level and dynamic soilstructure effects can be neglected. Lateral deflections and drifts of the flexible base models resting on soil class $\mathrm{D}_{\mathrm{e}}$ increase respectively by $3 \%, 10 \%$, and $19 \%$ in comparison to fixedbase models for 5, 10, and 15 storey models. Those increments, at least for 10 and 15 storey models, are potentially safety threatening as they can change the performance level of the mentioned building frames from life safe to near collapse.

For the models on soil class $E$, lateral deflections and drifts of the flexible base models have increased by $11 \%, 40 \%$, and $89 \%$ in comparison to fixed-base models for models S5, S10, and S15, respectively. Performance levels of S10 and S15 models change from life safe to near collapse level as shown in Figs. 6(b) and 7(b). Such a significant change in the interstorey drifts and subsequently performance level of 10 and 15 storey models resting on soil class $E_{e}$ is absolutely dangerous and safety threatening. Therefore, the conventional design procedure excluding SSI is no longer adequate to guarantee the structural safety for the mentioned mid-rise moment resisting building frames. Design engineers need to precisely take the effects of dynamic SSI into account in their design especially for construction projects on soft soils.

It can be noted that by decreasing the shear wave velocity and consequently rigidity of the subsoil, the difference between period of vibrations in two cases (structures with flexible and fixed bases) increase; as a result, the effects of soil-structure interaction for soil classes $D_{e}$ and $E_{e}$ are profoundly considerable while for relatively rigid ground (soil class $C_{e}$ ), it is negligible. Taking SSI effects into account, the spectral displacement $S_{d}$ changes considerably with change in natural period. Therefore, such increase in the natural period dominantly alters the response of the building frames under the seismic excitation. In the case of utilised mid-rise moment resisting building frames resting on soft soil deposits, natural period lies in the long period region of the response spectrum curve due to the natural period lengthening for such systems. 
Hence, the displacement response tends to increase, and eventually performance level of the structures can be changed from life safe to near collapse or total collapse.

\section{Conclusions}

According to the results of the numerical investigations conducted in this study for midrise moment resisting building frames resting on soil classes $C_{e}, D_{e}$ and $E_{e}$ according to the soil classification of AS-1170.4, it is observed that effects of dynamic soil-structure interaction for seismic design of mid-rise moment resisting building frames resting on soil class $\mathrm{C}_{\mathrm{e}}$ are insignificant.

It is also observed that dynamic soil-structure interaction has a profound influence on the seismic response of mid-rise moment resisting building frames resting on soil classes $\mathrm{D}_{\mathrm{e}}$ and $E_{e}$. Performance levels of the building frames change from life safe to near collapse in soil class $E_{e}$ which is dangerous and safety threatening. As a result, considering SSI effects in seismic design of moment resisting building frames resting on soil classes $D_{e}$ and $E_{e}$ (particularly $\mathrm{E}_{\mathrm{e}}$ ) is essential.

It can be concluded that the conventional design procedure excluding SSI may not be adequate to guarantee the structural safety of mid-rise moment resisting building frames resting on soft soil deposits. As most of the seismic design codes around the globe do not address the soil-structure interaction (SSI) explicitly, considering SSI effects in the seismic designs as a distinguished part of these standards is highly recommended. It is also recommended to engineering companies working in regions located in high earthquake risk zones, to consider dynamic soil-structure interaction effects in the analysis and design of mid-rise moment resisting building frames resting on soft soils to ensure safety of the design.

\section{References}

Agrawal, R. and Hora, M.S. (2012), "Nonlinear interaction behaviour of plane Frame-layered Soil system subjected to seismic loading”, Structural Engineering and Mechanics, 41(6), 711-734.

AS1170 (2007), Structural Design Actions, Standards Australia, NSW, Australia.

AS3600 (2001), Concrete Structures, Standards Australia, NSW, Australia.

ATC-40 (1996), Seismic Evaluation and Retrofit of Concrete Buildings, Applied Technology Council, Seismic Safety Commission, State of California.

Beaty, M.H. and Byrne, P.M. (2001), “Observations on the San Fernando Dams”, Proceedings of the 4th International Conference on Recent Advances in Geotechnical Earthquake Engineering and Soil Dynamics, San Diego, California, March .

Byrne, P.M., Naesgaard, E. and Seid-Karbasi, M. (2006), “Analysis and Design of Earth Structures to Resist Seismic Soil Liquefaction, in Sea to Sky Geotechnique”, Proceedings of the 59th Canadian Geotechnical Conference \& 7th Joint CGS/IAH-CNC Groundwater Specialty Conference, Vancouver, Canada, October.

FEMA 440, NEHRP Recommended Provisions for Improvement of Nonlinear Static Seismic Analysis Procedures (2005), ATC-55 Project, Emergency Management Agency, Washington, D.C.

Galal, K. and Naimi, M. (2008), "Effect of conditions on the response of reinforced concrete tall structures to near fault earthquakes”, Struct. Design tall Spec. Build., 17(3), 541-562.

Gazetas, G. and Mylonakis, G. (1998), Seismic soil-structure interaction: new evidence and emerging issues, 
Geotechnical Earthquake Engineering and Soil Dynamics, 10(2), 1119-1174.

Itasca Consulting Group (2008), FLAC2D: Fast Lagrangian Analysis of Continua, version 6.0, User's manual, Minneapolis.

Karamodin, A.K. and Kazemi, H.H. (2008), "Semi-active control of structures using neuro-predictive algorithm for MR dampers”, Structural Control and Health Monitoring, 17(3), 237-253.

Kausel, E. (2010), “Early history of soil-structure interaction”, Soil Dyn. Earthquake Eng., 30(9), 822-832.

Kobayashi, H., Seo, K. and Midorikawa, S. (1986), Estimated Strong Ground Motions in the Mexico City Earthquake: The Mexico Earthquakes 1985, Factors Involved and Lessons Learned, American Society of Civil Engineers, New York.

Kramer, S.L. (1996), Geotechnical Earthquake Engineering, Prentice Hall Civil Engineering and Engineering Mechanics Series.

Nakhaei, M. and Ghannad, M.A. (2006), "The effect of soil-structure interaction on hysteretic energy demand of buildings”, Structural Engineering and Mechanics, 24(5), 641-645.

NEHRP (2003), Recommended Provisions for Seismic Regulation for New Buildings and Other Structures, Part 2: Commentary FEMA 303, Federal Emergency Management Agency, Washington, DC, USA.

Paul Smith-Pardo, J. (2011), "Performance-based framework for soil-structure systems using simplified rocking foundation models”, Structural Engineering and Mechanics, 40(6), 763-782.

Rahvar (2005), "Geotechnical and Geophysical Investigations and Foundation Design Report of Musalla Construction Site in Tehran”, P. O. Rahvar Pty Ltd., 1, Tehran, 1-64.

Rahvar (2006a), “Geotechnical Investigations and Foundation Design Report of Kooh-e-Noor Commercial Building”, P. O. Rahvar Pty Ltd., Final Report, Tehran, Iran, 1-69.

Rahvar (2006b), “Geotechnical Investigations and Foundation Design Report of Mahshahr Train Station”, P. O. Rahvar Pty Ltd., Iran Railways Authority, Mahshahr, Iran, 1-42.

Rayhani, M.H. and El Naggar, M.H. (2008), "Numerical modelling of seismic response of rigid foundation on soft soil”, International Journal of Geomechanics, 8(6), 336-346.

Tabatabaiefar, H.R. and Massumi, A. (2010), "A simplified method to determine seismic responses of reinforced concrete moment resisting building frames under influence of soil-structure interaction”, Soil Dynamics and Earthquake Engineering, 30(11), 1259-1267.

Tabatabaiefar, H.R., Fatahi, B. and Samali, B. (2012), “An empirical relationship to determine lateral seismic response of mid-rise building frames under influence of soil-structure interaction”, The Structural Design of Tall and Special Buildings, DOI: 10.1002/tal.1058.

Veletsos, A.S. and Meek, J.W. (1974), “Dynamic behaviour of building-foundation system”, Journal of Earthquake Engineering and Structural Dynamics, 3(2), 121-138.

Vision 2000 Committee (1995), Performance Based Seismic Engineering of Buildings, Structural Engineers Association of California (SEAOC), Sacramento, CA.

Vucetic, M. and Dobry, R. (1991), "Effects of soil plasticity on cyclic response”, Journal of Geotechnical Engineering, 117(1), 89-100.

Wolf, J.P. and Deeks, AJ. (2004), Foundation Vibration Analysis: A Strength-of-Materials Approach, Elsevier, Oxford, UK.

Wolf, J.P. (1985), Dynamic Soil-Structure Interaction, Prentice-Hall Inc., Englewood Cliffs, New Jersey. 